\title{
Estudio, tratamiento lexicográfico y fuentes del Diccionario comercial de Domingo Gildo y Charles Le Touzé*
}

Study, lexicographical treatment and sources of Domingo Gildo and Charles Le Touzé's Diccionario comercial

\author{
$M^{a}$ ÁNGELES GARCÍA ARANDA \\ Universidad Complutense de Madrid \\ magaranda@filol.ucm.es
}

\begin{abstract}
Resumen: En el contexto de las transformaciones en el comercio nacional e internacional que se producen en la segunda mitad del siglo XIX, se publica el Manuel de correspondance commerciale en espagnol et en français (1857-1859) de Domingo Gildo y Charles Le Touzé. Este artículo presenta el contenido de la obra, explica la tradición en la que se incluye y, especialmente y dada su originalidad, aporta un estudio del tratamiento lexicográfico del Diccionario comercial que reúne.

Palabras clave: léxico comercial; siglo XIX; español; Domingo Gildo.

Abstract: In the context of the changes in national and international trade in the second half of the nineteenth century, is published the Manuel de correspondance commerciale en espagnol et en français (1857-1859) by Domingo Gildo and Charles Le Touzé. This paper presents an analysis of the work, the tradition in which it is inserted and, especially, a study of the lexicographical treatment of the Diccionario commercial.
\end{abstract}

Key words: commercial vocabulary; 19th century; Spanish; Domingo Gildo.

Fecha de presentación: 08/07/2018 Fecha de aceptación: 17/12/2018

\section{INTRODUCCIÓN}

El desarrollo de las relaciones comerciales es, sin la menor duda, uno de los más preciosos resultados debidos a los grandes descubrimientos que han visto la luz en nuestro siglo. Con el vapor y la electricidad no existen ya las distancias; el comercio repartidor de los frutos de la tierra y de los productos del entendimiento, es el vínculo que une hoy entre sí todos los pueblos del globo, $\mathrm{y}$, el comerciante ha venido a ser ciudadano del mundo (p. II)

Con estas palabras el profesor, lexicógrafo y gramático Domingo Gildo justifica la necesidad de «tener que corresponder en diferentes idiomas» $y$, como consecuencia, la

\footnotetext{
* Este trabajo se enmarca dentro del Proyecto de Investigación «Biblioteca Virtual de la Filología Española. Fase III: nuevas bibliotecas y nuevos registros. Información bibliográfica. Difusión de resultados» (FFI201782437-P).

$\mathrm{M}^{\mathrm{a}}$ ÁNGELES GARCÍA ARANDA, «Estudio, tratamiento lexicográfico y fuentes del Diccionario comercial de Domingo Gildo y Charles Le Touzé», Revista de Lexicografia, XXIV (2018), pp. 51-78 ISSN: 1134-4539, e-ISSN: 2603-667. doi: https://doi.org/10.17979/rlex.2018.24.0.5517
} 
publicación de un diccionario comercial «útil a la par que nuevo» que satisfaga las necesidades lingüísticas que impone el nuevo escenario comercial europeo.

Las transformaciones en el comercio nacional e internacional, debidas, principalmente, a la industrialización, al desarrollo de los transportes, al perfeccionamiento de las comunicaciones y al incremento de la banca que se producen en la segunda mitad del siglo XIX, tuvieron consecuencias lingüísticas: la composición y publicación de artes y manuales de correspondencia destinados a la enseñanza de español comercial, pues el nuevo escenario económico demandaba profesionales bien formados tanto en comercio como en las lenguas de las naciones con las que tenían que llevarse a cabo las relaciones comerciales.

En este contexto, Domingo Gildo, con la colaboración de Charles Le Touzé, da a la imprenta un Manuel de correspondance commerciale en espagnol et en français (18571859) que compendia, por un lado, modelos de cartas comerciales y, por otro, un interesante y original corpus léxico que puede ayudar a entender cómo se produjo la recepción de galicismos y voces extranjeras en obras menos conocidas del siglo XIX, cómo se plasmó esta en la lexicografía y cómo se enfrentaron a ella estos autores. Este artículo presenta el contenido del Manuel, el contexto en que fue compuesto y, especialmente, un estudio del tratamiento lexicográfico y de las fuentes utilizadas para la composición del léxico comercial que reúne en la segunda parte de la obra.

\section{LOS MANUALES DE ESPAÑOL COMERCIAL EN FRANCIA}

Aunque las relaciones políticas, económicas y sociales entre Francia y España habían favorecido la publicación de gramáticas y diccionarios del español desde el siglo XVI, es en el siglo XIX cuando se produce el mayor desarrollo en la edición y publicación de manuales de enseñanza de español como segunda lengua, situación que se ve, además, favorecida por los beneficios económicos que proporcionaba la industria del libro y por «l'introduction des langues vivantes dans les programmes de l'enseignement secondaire, à titre facultatif en 1829, puis comme discipline obligatoire à partir de 1838» (Choppin, 1995: 19).

Pero junto a la lengua general, es necesario atender también otras necesidades surgidas del contacto entre las dos naciones, especialmente en el contexto de intercambios mercantiles, por lo que aparecen los primeros centros de enseñanza especializada a imitación de los alemanes ${ }^{1}$, se incluyen materias específicas en los planes de estudio de las escuelas secundarias ${ }^{2}$ y se publican los primeros textos destinados exclusivamente al español especializado, técnico o comercial.

\footnotetext{
${ }^{1}$ En 1819, por ejemplo, se funda la École Supériure de Commerce de París, en 1866 la de Mulhouse, en 1871 la de Havre, en 1872 la de Lyon y la de Marsella, en 1874 la de Burdeos, en 1892 la de Lille, en 1895 la de Ruan, en 1896 la de Nancy, en 1897 la de Montpellier, en 1881 la École des Hautes Études Commerciales de París y en 1884 el Institute Commercial de París.

${ }^{2}$ Para estos centros de formación especializados se compusieron, entre otros, el Cours gradué de langue et de littérature espagnole. Première partie: grammaire espagnole. À l'usage des écoles spéciales du commerce et des établissements professionnels de Jean-Joseph Gely (París, Hennuyer, 1865), el Epitome de la grammaire de la langue espagnole ou Coup d'œil sur les règles les plus usitées. À l'usage de l'École de commerce de Lyon (Lión, Pelagaud, 1873), el Manuel d'espagnol comercial à l'usage des écoles supérieu-
} 
El corpus de textos sobre español comercial en Francia hay que contextualizarlo dentro de la producción europea del mismo tema, pues, en la práctica totalidad de los países del entorno, editores, autores e impresores se percataron de las ganancias que reportaban estas obras y se afanaron a lo largo de toda la centuria en la composición y publicación de diccionarios y artes de correspondencia comercial ${ }^{3}$.

Estos últimos, además del léxico, incluían modelos de correspondencia comercial, contenido que debía resultar muy útil a comerciantes, banqueros y negociantes, sobre todo si estaba traducido o adaptado a varias lenguas. Entre los publicados en Francia sobre español comercial se encuentran (cfr. Choppin, 1995): el Manuel de correspondance commerciale en espagnol et en français de Domingo Gildo y Charles Le Touzé (1857-1859), la Nueva correspondencia comercial francesa-española de José M. Lopes (París, Truchy, 1863), el Manuel pratique de correspondance espagnole de Giovanni Battista Melzi (París, Le Clerc et $C^{\text {ie }}, 1878$ ), versión española de un texto que se publicó en otras muchas lenguas ${ }^{4}$ y L'espagnol commercial de Emmanuel Contamine de Latour (París, Librería Larousse, 1890).

Estos textos profundizan en la correspondencia comercial y en el léxico (para otros fines ya existían diccionarios, gramáticas y manuales varios), pues el lenguaje de los negocios exige conocer el vocabulario de este tecnolecto y la forma de las cartas y escritos que para esta actividad se redactan, pues hay diferencias considerables entre componer una circular, un ofrecimiento de servicio o una operación comercial.

En este sentido, el Manuel de correspondance commerciale en espagnol et en français de Domingo Gildo y Charles Le Touzé es uno de los más interesantes, pues, aunque no es demasiado original ni extenso en la parte de la correspondencia, el vocabulario que reúne en las páginas finales, sin embargo, es, como se verá a continuación, una fuente muy rica para la lexicografía histórica especializada del español.

res de commerce, des clases de l'enseignement secondaire moderne, des écoles primaires supérieures, des négociants et des employés de commerce de Théophile Alaux (París, Garnier, 1896) o el Cours de langue espagnole. Première année. À l'usage des clases de l'enseignement secondaire, des écoles comerciales et professionnelles, des écoles primaires supérieures et des cours commerciaux de J. Parrain (Burdeos, Lafitte-Muller-Parrain, 1899).

${ }^{3}$ Así, por ejemplo, en Inglaterra aparecen el Crosby's merchant's and tradesman's pocket dictionary de Benjamin Crosby (Londres, by a London Merchant, 1808) y A General Dictionary of Commerce, Trade and Manufactures de Thomas Mortimer (Londres, Richard Phillips, 1810); en España se publica el Diccionario de hacienda, con aplicación a España de José Canga Argüelles (Madrid, s. n., 1833-1834); en Italia sale a la luz la Encipledia del negoziante, ossia gran dizionario del commercio (Venecia, Giuseppe Antonelli, 1839); en Alemania se imprimen el Universal-Lexikon für kaufleute und Fabrikanten de Jonh Ramsay McCulloch (Ausburgo, Jenisch und Stage'sche Buchhandlung, 1842) o el Otto Spamer's illustriertes Handels-Lexikon de Otto Spamer (Leipzig, 1876).

En Francia, por su parte, salen a la luz los repertorios de Petijean (París, s. n., 1827), de Briand de Verzé (París, Langlois fils, 1830), de Eusèbe Girault de Saint-Fargeau (París, Didot, 1844-1846), de Auguste Sacré (París, Marescq aîné, 1884) o de Pigier (París, Libraire de l'École pratique de commerce, 1899), entre otros.

${ }^{4}$ Las obras en otras lenguas, publicadas todas en París en 1878, son el Manuel practique de correspondance anglaise, el Manuel practique de correspondance allemande y el Manuel practique de correspondance italienne. 


\section{El MANUEL DE CORRESPONDANCE COMMERCIALE DE DOMINGO GILDO Y CHARLES LE TOUZÉ}

\subsection{Los autores y sus obras}

Domingo Gildo (1820-¿?), según consta en varias portadas de sus obras, fue profesor del Collège Chaptal y de la Ėcole Commerciale de París. El primero es una institución fundada por Prosper Goubaux, precursor de la enseñanza moderna de ciencias y técnicas, en 1844 en honor a Jean-Antoine Chaptal, químico, ministro del Interior y renovador de la instrucción pública francesa, que nació con el deseo de ofrecer «aux jeunes gens qui se destinent au commerce et à l'industrie avec des études plus spéciales, mieux appropriées que celles des lycées à leur future carrière, une éducation propre à élever les coeurs et les esprits» ${ }^{5}$. La segunda es un centro de enseñanza media (para la educación especializada superior ya estaba la École supérieure de commerce, 1819) creado en 1863 por el secretario de la Cámara de Comercio de París Guillaume Denière para la formación de empleados de banca y comercio (cfr. Chambre de Commerce et d'Industrie de Paris, 1988).

Además de su labor en estos centros educativos, Domingo Gildo, según consta en las páginas finales de algunas de sus obras, impartía cursos de español de dos tipos: «les parties du discours et la traduction de l'espagnol en français» o bien «la conversation, la traduction du français en espagnol, la syntaxe, les exercices, la correspondance commerciale et privée» (Gildo-Le Touzé, 1857-1859), con unas tarifas que dependían del número de alumnos y del lugar en que se dieran las clases ${ }^{6}$.

Su interés y su preocupación por la docencia del español y del francés le llevaron a publicar varias obras para la formación en estas dos lenguas. Así, es autor de una Grammaire théorique et pratique de la langue espagnole (París, l'auteur, 1856), de una Gramática teórico-práctica de la lengua francesa (París, Bergelot, 1861), de un Dictionnaire espagnol-français et français-espagnol (Madrid, Gaspar y Roig, 1850), de un Diccionario francés-español y español-francés (París-México, Bouret, 1885), de un Cuadro sinóptico de los verbos franceses (París, Bergelot, 1862), de un Tableau synoptique des verbes français (París, Bergelot, 1862), de un Cahier pour la conjugaison des verbes (París, V. Goupy, 1863), de un Manual de conjugación, sistema muy sencillo para la conjugación de los verbos franceses regulares e irregulares (París, Bergelot et J. Cosnard, 1864) y de París en la mano (París, Bergelot, 1867)-Paris en la mane (París, Bergelot, 1867).

Por su parte, el economista parisino Charles Le Touzé escribió un Traité théorique et pratique du change des arbitrages et des matières d'or et d'argent, contenant les

\footnotetext{
${ }^{5}$ Palabras extraídas de «Faits historiques» de la página web del Collège et Lycé Chaptal, https://www.acparis.fr/serail/jcms/s2_1622763/fr/faits-historiques

${ }^{6}$ El mes completo con tres clases a la semana costaba 10 francos; las clases particulares mensuales, por su parte, costaban 30 francos si las impartía a un alumno, 40 a dos y 50 a cuatro en su casa (Boulevard BonneNouvelle, 35, en face le Théatre du Gymnase), pero si las impartía en casa del alumno el precio ascendía a 50,60 y 80 francos, respectivamente. Advierte tras indicar sus honorarios que «tout mois comencé se paye en entier», que «le mois comencé à compter du jour ouè l'on prend la première leçon» y que «on paye d'avance» (Gildo-Le Touzé, 1857-1859).
} 
changes et les monnaies des principales places de commerce du monde (París, Guillaumin, 1859).

Ambos especialistas se unen para «dotar el comercio con una obra útil a la par que nueva, publicando un Diccionario de la correspondencia comercial español-francés y francés-español», tarea «larga y difícil» por ser «los primeros en haberla emprendido» (pp. V-VI).

El Manuel de correspondance commerciale en espagnol et en français suivi d'un Dictionnaire français-espagnol et espagnol-français ${ }^{7}$ fue encuadernado en octavo y consta de dos partes. La primera corresponde al Manuel y fue impresa en 1859 por Bonaventure et Ducessois, editada por Bergelot y podía adquirirse tanto en la librería de este (Boulevard Poissonnière, 17) como en la de C. Moro y $\mathrm{C}^{\text {ia }}$ (Madrid, Plaza del Sol, 5, 7 y 9). La segunda, con portada y paginación diferentes, pertenece al Dictionnaire commercial espagnol-français, contenant tous les mots employés dans les affaires commerciales, les principaux termes de bourse et de banque, les divers objets de la fabrication, les produits chimiques, la droguerie, les minéraux, les végétaux, etc., que fue impreso en París en 1857 por los libreros-editores Stassin y Xavier. El texto se reimprimió, al menos, en cuatro ocasiones más; la última en 1877 por Dramard-Baudry ${ }^{8}$.

\subsection{Paratextos}

El Manuel comienza con una introducción redactada en las dos lenguas (las páginas pares para el español y las impares para el francés) en la que se exponen las razones por las que los autores han emprendido la redacción de su obra, así como el contenido detallado de las páginas que la integran.

El desarrollo del comercio producido en los últimos años gracias al «vapor y a la electricidad» (p. II) han acarreado «el tener que corresponder en diferentes idiomas, siendo esta necesidad la consecuencia natural del progreso mercantil» (p. III). Ante los nuevos desafíos mercantiles, el comerciante necesita de textos que lo ayuden en su quehacer diario, pues aunque «para la mayor parte de los idiomas hay diccionarios de traducción recíproca, estos libros, compuestos por lo regular con una mira literaria, mal podrían encontrar los negociantes, banqueros y comerciantes, esas frases especiales, esos términos técnicos que constituyen lo que se llama, el lenguaje comercial» (p. IV), por lo que Gildo y Le Touzé se proponen satisfacer estas necesidades. Para ello diseñan una obra bilingüe español-francés dirigida «particularmente a todos aquellos que, en relación directa con la Francia, la España o los estados de América del Sur, se hallan obligados a escribir la correspondencia en el idioma de sus clientes» (p. IV).

El Manuel, por estas razones, se compone de dos partes redactadas también en las dos lenguas: la primera dedicada a la correspondencia comercial incluye una «ligera indicación del estilo y reglas que deben observarse en la correspondencia comercial» (p. IV), fraseología comercial, algunos modelos de cartas y de documentos útiles para el comer-

\footnotetext{
${ }^{7}$ Utilizo el ejemplar que se encuentra en la Biblioteca Nacional de Francia con signatura X-25681, digitalizado en https://gallica.bnf.fr/ark:/12148/bpt6k318643d.

${ }^{8}$ Para todos los ejemplares citados cfr. Choppin (1995), Esparza y Niederehe (2012 y 2015) y Biblioteca Virtual de la Filología Española, https://www.bvfe.es/.
} 
ciante, un cuadro comparativo de monedas, pesos y medidas y una lista de las principales abreviaturas empleadas en el comercio. La segunda parte contiene el repertorio lexicográfico, un vocabulario geográfico y una lista de nombres «afín de evitar los errores de ortografía que se cometen ordinariamente en los sobrescritos de las cartas» (p. VI).

Pese a la estructura de la obra y a pesar también de las ventajas para comerciantes y mercaderes de todos los contenidos reunidos en el Manuel, Gildo y Le Touzé consideran que la segunda parte de la obra «es la más importante» $\mathrm{y}$ «ha de ser de grande utilidad y provecho para el comercio» ( $\mathrm{p}$. VI), pues las denominaciones en francés de productos y mercancías pueden ocasionar problemas de comprensión entre los comerciantes o, lo que es peor, arruinar ventas causando así grandes pérdidas de tiempo y de dinero ${ }^{9}$. Esas dificultades pueden

allanarse por medio de nuestro diccionario, porque, no solo se encuentra en él la traducción recíproca de los términos mercantiles usados en ambos idiomas, sino que también se halla la denominación de las diferentes mercancías que se espiden hoy a todas partes. Por este medio, todo comisionista, todo comerciante, podrá comprender los pedidos que le hicieren y ejecutarlos sin demora ni temor de equivocarse (p. VIII).

\subsection{La correspondencia y la fraseología}

Para Gildo y Le Touzé se juzga a una casa de comercio por su correspondencia, por lo que es imprescindible conocer y manejar la forma y el contenido de los escritos que se producen en este ámbito. En este sentido, recuerdan que no consiste «el escribir bien una carta de comercio en el estilo elevado ni en la pureza del lenguaje, sino en la claridad con que se trata el asunto de que se escribe» (p. X) y recomiendan evitar la prolijidad, las frases ambiguas, las exclamaciones, los retruécanos, las inversiones, las circunlocuciones, las frases interpuestas, conocer las abreviaturas, componer periodos cortos y claros, emplear construcciones rectas y un estilo sencillo y no abusar de la trivialidad, «en una palabra, es menester escribir como si se estuviese hablando con el sujeto a quien se escribe» (p. XII).

Tras la explicación del concepto de carta comercial y de sus requisitos, y como es habitual en este tipo de obras, los autores incluyen varios modelos de circulares, peticiones de informes, cartas de recomendación, envíos de letras de cambio, cartas de expedición y sus respectivas respuestas, así como modelos de recibos, de pagarés, de facturas, del libro diario, del libro mayor y de cuentas corrientes, si bien advierten que «no nos hemos propuesto hacer un tratado de contabilidad, solo ha sido nuestra inten-

\footnotetext{
${ }^{9}$ Merece la pena leer la cita completa: «los géneros de fabricación francesa, y particularmente los artículos de París, que la Francia expide en tanta cantidad a los países meridionales, han recibido sus nombres en francés, lo que forma algunas veces un neologismo estraño y caprichoso. En España y en los diversos países de la América del Sur se han traducido estas voces, o se les ha puesto otras equivalentes en español, pero cada uno lo ha hecho a su manera, según su inspiración, y casi todos diferentes, resultando una verdadera dificultad para la expedición de mercancías. Por otra parte, la novedad de los géneros y su actualidad, no permiten a veces arriesgar un envío o pedir explicaciones; forzoso es comprender y expedir, no importa cómo, so pena de malograr la ocasión de vender. La moda caprichosa e inconstante por naturaleza no admite ninguna dilación» (pp.VI y VIII).
} 
ción el presentar algunos ejemplos en que se hallan los términos más generales de teneduría de libros» (p. 59) ${ }^{10}$.

Ni la utilización de la tipología epistolar en la enseñanza de lenguas ni la consideración de que las cartas son conversaciones escritas son nuevas en la Historiografía lingüística. Desde la Edad Medida muchos fueron los manuales que con los títulos de secretario, escribiente, tratado de cartas misivas o manuales de correspondencia se compusieron para la formación tanto en lengua materna como de segundas lenguas en toda Europa, y, especialmente desde el siglo XVIII, para la formación de comerciantes.

Gildo y Le Touzé se limitan, pues, a adaptar los contenidos clásicos y a presentarlos de forma fácil y accesible, pues consideraron que la mejor manera de adiestrar a estudiantes y comerciantes era a través de las cartas y es que «es menester que esta [la carta] sea enteramente comercial para que cuantos la lean formen un juicio aventajado del que la firma» (p. X).

De la página veintidós a la página cuarenta y tres se extiende una «Fraseología comercial» que reúne una serie de frases a dos columnas destinadas a ser usadas en distintos momentos de las cartas y que bien podrían alternar con las que se incluyen en el corpus de cartas anterior.

En suma, cartas, frases y modelos comerciales que ponen de manifiesto los recursos utilizados para llevar a cabo las complejas y espinosas, en ocasiones, relaciones mercantiles entre los negociantes.

\subsection{Los diccionarios: estructura y contenido}

Los repertorios lexicográficos de Gildo y Le Touzé son alfabéticos y se dividen en dos partes: las primeras páginas las ocupa el Dictionnaire commercial espagnolfrançais y las últimas el Diccionario comercial francés-español.

Recogen, como consta en las portadas, «todas las voces empleadas en los negocios mercantiles», voces que «pertenecen exclusivamente al lenguaje mercantil, por consiguiente no se hallan en ningún otro [diccionario], y en caso de hallarse no tienen la acepción puramente comercial que les hemos dado aquí», pero, pese a la originalidad que pregonan su autores, no hacen sino continuar con una corriente comenzada en la centuria anterior (Garriga Escribano, 1996 y Gómez de Enterría, 1996).

Temáticamente, y como también se dice en la primera página, dan cabida a los «principales términos de la bolsa y del banco, los diversos objetos de la fabricación, los productos químicos, droguería, minerales, vegetales». Así, hay sustantivos sobre materias y productos con las que se mercadeaba (abadejo, abanico, concha, coliflor, orégano, oboe, orejones, oro, paca de algodón, palangana, palillos, papel, peinecillos para los rizos, pieles, pimienta, pruebalicores, puerro, purpurina, puzol, rábano, reloj, ribetillos, ron, ropa blanca, rosario, sábana, saco, sal, sándalo, tabaco, tafetán, tomate, tomillo, zarcillos), adjetivos para describir estos productos (aborlado, aceptable,

\footnotetext{
${ }^{10}$ Para quienes deseen profundizar en conocimientos de contabilidad, Gildo y Le Touzé recomiendan las obras editadas por Pablo Leclerc.
} 
acolchado, amarillo, moreno, rubia, roto, sencillo, silvestre, tornasolado, tupido), nombres de la química, droguería, minerales y vegetales (alcaravea, aguarrás, aleta de ballena, azabache, bergamota, beleño, cardenillo, ébano, esencia de santónico, euforbio, hidrosulfato, natrón, nuez vómica, salsomosa, tusilago, yerba pajarera, zaragato$n a$ ), voces que designan acciones habituales o importantes para los negocios (confiar, naufragar, negar, obrar, obligarse, operar, oponerse, pagar, paralizar, perder, preparar, producir, prohibir, prolongar, proponer, proveer, quedar, realizar, rebajar, recoger, recomendar, reducir, reembolsar, renunciar, romper, saldar, sobrecargar, solicitar, sostener, tasar, temporizar, traer, traficar) y voces que se podrían considerar técnicas relativas al comercio (amortización, contabilidad, contrato, contravalor, orden, pagadero, participación, perjuicio, plazo, pleito, póliza, portador, precio, quiebra, remesa, renta, sociedad, subida de precios, tesoro, valor, vencimiento).

En los repertorios de Gildo y Le Touzé se encuentran juntas, por tanto, voces de la lengua general y términos propios del tecnolecto comercial, y, dentro de estos últimos, términos integrados y términos especializados de varios niveles (léxico especializado banalizado, léxico especializado de tronco común, léxico especializado básico o fundamental, léxico ultraespecializado), lo que supone encontrar en estas páginas discurso divulgativo o didáctico y discurso especializado (Cabré, 1993 y 1999, Gutiérrez Rodi1la, 1998 y 2005).

Los artículos lexicográficos, por su parte, son muy sencillos, de manera que suelen estar formados por la entrada española + categoría gramatical + [en el caso de los verbos, un número que remite a la parte de las conjugaciones en su gramática] + equivalente/s de distinto tipo + [pseudodefinición] en francés, y lo mismo, pero a la inversa, para la parte francés-español.

1) Artículos: entrada ${ }^{11}+$ equivalentes sinonímicos simples/complejos o perifrásticos Abastecimiento, m. Approvisionnement, achalandage.

Colcha, f. Courte-pointe.

Coliflor, f. Choux-fleur.

Compra, f. Achat, emplette.

Diariamente, ad. Journellement.

Gordo, a. Gros, gras.

Gramil, m. Trusquin.

Grana, a. Escarlate, cochenille.

Gueridón para salvillas, $\mathrm{m}$. Guéridon pour pots à crème.

Harpón, m. Harpon.

Importador, m. Celui qui fait l'importation.

Lanilla, f. Etoffe de laine très légère.

Lápida, f. Pierre portant une inscription.

Lista, f. Lista, banda, raie.

Litigio, m. Litige.

Llanamente, ad. Franchement, sans détour.

${ }^{11}$ En algunas ocasiones, las entradas o lemas son dobles, formadas por dos o más variantes formales: Bihuela o Bigüela, Canuto o Cañuto, Empastado o en pasta, Filadiz o Filaiz, Ónice, Ónique, Ónix, Óniz, Plumión o Plumón. 
Llano, a. Uni, égal, doux, affable.

Llavero, m. Anneau pour tenir des clefs.

Llano, a. Plaine.

Llapa, f. La quantité de mercure qu'on ajoute à un métal pour le travailler.

Medallón, m. Médaillon.

Marinero, m. Matelot.

Marrano, m. Cochon, porc.

Masa, f. Pâte, masse, mélange de métaux.

Minuteros, m. Aiguilles de montre (ou) de pendule.

Novación, f. Renouvellement, transmutation.

Ostrón, m. Grosse huître d'Amérique.

Paladeo, m. Service de procelaine (ou) de cristal composé de petites pièces.

Postura, f. Prix mis par un enchérisseur.

Rengue, m. Gaze de fil (ou) de coton.

Topacio, m. Topaze.

Tormenta, f. Tempête, malheur.

2) Artículos: entrada + equivalente + pseudodefinición

Brasero, m. Brasier, basin de métal dont on sert en Espagne pour chauffer les appartements

Galène, f. Galène, mine de plomb.

Herrumbre, f. Rouille, scorie de fer.

Holandilla, f. Holandille, petite batiste.

Instrumento público, $\mathrm{m}$. Titre, acte destiné à constater un fait.

Jarope, m. Julep, potion médicinale.

Mechoacán, m. Mechoacan, rhubarbe blanche.

Marchamar, v. Douaner, marquer les marchandises à la douane.

Molinillo, m. Moussoir, petit moulin à café.

Mosquitero, m. Mouchette, papillon de gaze pour se garantir de moustiques.

Natrón, m. Natron, matière saline.

Ochavado, a. Octogone, à huit côtés.

Ofrecedor, m. Soumissionnaire, celui qui offre de se charger de.

Pendiente, a. Pendant, qui n'est pas terminé.

3) Artículos: entrada + número con información sobre conjugación verbal + equivalente

Abastecer, v. ir. (128). Approvisionnet, achalander.

Comprometerse, v. (1-XV). S'engager.

Fallecer, v. ir. (128). Mourir.

Invertir, v. ir. (130). Intervertir.

Ofrecer, v. ir. (128) Offrir, soumissionner.

Utilizar, v. (1-X). Utiliser. 
Dada la sencillez del repertorio lexicográfico, la mayoría de los artículos son sencillos, si bien no faltan casos, sobre todo aquellos que recogen mercancías y voces del comercio, en los que aparecen diversas unidades pluriverbales ${ }^{12}$ :

Abanico, m. Éventail - Abanico barillage de marfil; éventail d'ivoire - Abanico calado; éventail découpé - Abanico esculpido; éventail sculpté.

Comercio, m. Commerce, négoce, trafic - Bolsa de comercio; bourse de commerce - Fondo de comercio; fonds de commerce - Comercio de negros; traite des nègres - Diario de comercio; journal de commerce.

Endoso, m. Endos, endossement - Endoso de una letra; endos d'un effet Endoso en blanco; endos en blanc - Endoso lleno; endos rempli - Endoso de fianza; aval, caution.

Fósforos, m. Amorcer, allumettes - Fósforos en palillos; allumettes en bois Fósforos en cerillas; allumettes en bougies.

Hierro, m. Fer - Hierro cabilla; fer en barres forgées - Hierro carretil; fer en barres de 5 pouces de large et 1 d'épaissuer - Hierro cellar; fer en barres de 3 pouces de large et 1 d'épaisseur - Hierro cuadrado, fer carré de 4 pouces Hierro torchuelo, fer carré de 3 pouces - Hierro varillas; fer à barres rondes Hierro en planchas; fer en plaques - Hierro en hojas; fer en feuilles - Hierro afinado; fer raffiné - Hierro forjado; fer forgé - Hierro albo; fer rouge Hierro para cepillo, fer à rabot.

Mano, f. Main - Mano de papel; main de papier - Dar de mano a; abandonner, rejeter quelqu'un - Dar la mano a; aider quelqu'un - De la mana a la otra; de la main à la main - Estar mano sobre mano; être à rien faire - No dejar una cosa de la mano; poursuivre une affaire sans relâche - Ganar por la mano; prendre le devant - Traer entre manos; avoir une affaire entre les mains.

Merluza, f. Merluche - Merluza seca; stockfish.

Sociedad, f. Société - Sociedad anónima; société anonyme - Sociedad por acciones; société par actions - Sociedad colectiva, en nombre colectivo; société en nom collectif - Sociedad en comandita, comanditaria; société en commandite - Acta de sociedad; acte de société - Contrato de sociedad; contrat de société.

En otras ocasiones, las unidades pluriverbales solo sirven, dado que el repertorio solo contiene equivalencias en las dos lenguas, para diferenciar acepciones de la voz: brocha para la barba/brocha para pintores, caña de azúcar/caña de pescar, diente de leche/diente de ajo, mazo de batir/mazo de plumas, pipa de aguardientelpipa para fumar.

Como puede verse, es habitual que los lemas de los sustantivos coincidan con la forma de estos en singular, si bien hay algunos casos en que el diccionario emplea diferentes artículos lexicográficos para las formas en singular y en plural, sobre todo en aquellos en los que el uso del plural es mayoritario (concha-conchas, piel-pieles, bala-

\footnotetext{
${ }^{12}$ A veces las unidades pluriverbales consituyen artículos lexicográficos diferentes: «Botella, d. Bouteille // Botellas de dos picos. Bouteille à syphon // Botellas de cristal. Bouteilles de cristal - Botellas lisas; bouteilles unies»; «Cabretilla, f. Peau de chevreau // Cabretillas negras mate. Chevreaux noir mat»; «Punto, $\mathrm{m}$. Point - A punto de vencer; sur le point d'échoir // Punto de estambre, m. Tricot de laine // Punto de encaje, m. Dentelle // Punto de malla, m. Filet // Punto de tul, m. Broderie sur tulle»; «Ropa, f. Hardes, habits, étoffes // Ropa blanca, f. Linge // Ropas hechas, f. Habits confectionnés».
} 
balas, botella-botellas, piedra-piedras), o bien solo incluye las formas plurales (lentejas, peinetillas, peladillas, pocillos, flores de mano, ribetillos).

Por otro lado, la polisemia y la homonimia parcial de algunas voces se manifiestan, en algunas ocasiones, en artículos lexicográficos diferentes, y son la información gramatical, las diferentes equivalencias y la información entre paréntesis las que ayudan a diferenciar acepciones y significados. Así, por ejemplo, «brillante, m. Brillant» aparece junto a «Brillantes, m. Diamants, brillants», «Brillo, m. Clinquant» junto a «Brillo, a. Éclat, brillant»», «Colchado, a. Ouaté» junto a «Colchado, m. Bourrelet», «Florete, m. Fleuret (toile)» junto a «Florete, a. Surfin» y a «Floretes, $\mathrm{m}$. Fleurets (arme)», «Lapicero, m. Porte-crayon» junto a «Lapicero, m. Crayon (bois)», «Listado, m. Rayure» junto a «Listado, p. p. (V. Alistado)» y a «Listado, a. Rayé», «Pendiente, a. Pendant, qui n'est pas terminé» junto a «Pensientes, m. Boutons (ou) boucles d'oreille», «Pensamiento, $\mathrm{m}$. Pensée» junto a «Pensamiento, m. Pensée (fleur)» $\mathrm{o}$ «Ridículo, $\mathrm{m}$. Sac à ouvrage» junto a «Ridículo, a. Ridicule».

De nuevo son la sencillez y la simplicidad del repertorio las que obligan, en no pocos ejemplos, a incluir paréntesis con remisiones internas ${ }^{13}$ (envuelta-frazada, huacalbocoy, matorral-brezo, oliva-aceituna, perol-cazo, sacabuche-trombón, serafinaestambre) o con diversas informaciones para ayudar al usuario a interpretar y delimitar significados, usos o formas:

Calzapollos, m. Calzapollos (chaussure d'Amérique).

Coriandro, m. Coriandre (plante).

Corinto, a. Corinto (couleur).

Cúrcuma, f. Curcuma (safran des Indes).

Chichonera, f. Bourrelet (coiffure d'enfant).

Chupador, $\mathrm{m}$. Hochet (jouet qu'on donne aux petits enfants pour presser les gencives).

Examinar (en parlant des experts): expertiser.

Gamuza, f. Chamois (peau).

Gordolobo, m. Bouillon-blanc (plante).

Jibia, f. Sèche (poisson).

Litócola, f. Lithocolle (ciment).

Loneta, (diminutif de lona).

Maravedís, m. Marevedis (Monnaie de cuivre d'un peu plus d'un centime.

L'adoption du système décimal à fait retirer cette monnaie de la circulation).

Margarita, f. Marguerite (fleur).

Martingal, $\mathrm{m}$. Martingale (circonférence en ivoire pour le harnachement des chevaux).

Octante, m. Octant (instrument astronomique).

Orellana, f. Orellana (teinture du roucou).

Orleans, m. Orléans (étoffe).

Pespunte, m. Piqûre (couture).

\footnotetext{
${ }^{13}$ Muchas veces estas remisiones no sino variantes formales: fierro-hierro, guantelete-gantelete, hipecacuana-ipecacuana, ládano-lábdano, lezna-lesna, locomotura-locomotiva, mecoacán-mechoacán, meriñaque-miriñaque, papas-patatas, toalla-toalla, yerro-error, yezgo-yesgo.
} 
Quieselspato, m. Quieselspath (minéral).

Quilograma, f. Chilogramme (section du germe antrophion de la famille des fougères).

Rosolí, m. Rossolis (liqueur).

Sobaqueras para vestidos, f. Sous-bras (morceau de caoutchouc qu'on met pour empécher que la sueurne tache les robes sous les bras).

Tembleques, m. Pampilles (ornement de coiffure).

Torongil, m. Mélisse, citronnelle (plante).

Tupido, a. Serré (en parlant des tissus).

Valenciana, f. Valencienne (dentelle).

Verbena, f. Verveine (plante).

Zapote, m. Sapotillier (arbre), sapotille (fruit).

Zurcir, v. Rentrer (terme de couture).

En suma, un repertorio concebido para facilitar la comunicación en las transacciones comerciales entre los dos países, que intenta allanar todas las dificultades del léxico $\mathrm{y}$ exponerlo de forma sencilla y útil.

\subsection{Estudio, tratamiento lexicográfico y fuentes del Diccionario comercial}

Más interesante que el análisis del contenido del Diccionario de Gildo y Le Touzé, es el estudio del corpus léxico que compendian, pues resulta una fuente riquísima para documentar voces neológicas y procedimientos utilizados para la formación de palabras nuevas, para mostrar los recursos utilizados en la adaptación de extranjerismos, para comprobar la vigencia de los términos que entraron en los diccionarios de la primera mitad del siglo XIX y para clasificar y caracterizar los que todavía no han entrado.

El repertorio de Gildo y Le Touzé, por ejemplo, recoge numerosas voces neológicas que no aparecen en el repertorio vigente en el momento de la Academia Española (edición de 1852), lo que no es infrecuente en la lexicografía no académica decimonónica. Como se ha dicho en repetidas ocasiones al tratar sobre los diccionarios de Melchor Manuel Núñez de Taboada, de Vicente Salvá, de Adolfo de Castro y Rossi, de Ramón Joaquín Domínguez o de la editorial Gaspar y Roig, los lexicográficos del XIX quisieron superar el repertorio de la Real Academia (en cuyo prestigio, por otro lado, se apoyaban) incorporando, por un lado, voces de la ciencia y de la técnica que designaban las nuevas realidades surgidas en la época, y, por otro, americanismos ${ }^{14}$.

En este sentido, necesario es reconocer que la lengua francesa, desde el siglo XVIII, fue la lengua vehicular en la comunicación científica, de modo que tanto las traducciones de autores franceses como la labor de los lexicógrafos (muchos de ellos autores

\footnotetext{
${ }^{14}$ Para la labor de los lexicógrafos decimonónicos no académicos, véase Alvar Ezquerra (1987a), Anglada (1997-1998), Azorín Fernández (2002, 2002-2004, 2003a, 2003b, 2007, 2008, 2012), Azorín Fernández y Baquero Mesa (2007), Bueno Morales (1996), Esparza (1999), García Belmar y Bertomeu Sánchez (1999), Garriga Escribano (1996-1997, 2003 y 2018), Gutiérrez Cuadrado (2001 y 2004), Iglesias Martín (2008), Seco $(1987 a, 1987 b$ y $1987 c)$.
} 
también de diccionarios bilingües con el francés ${ }^{15}$ ) fueron determinantes para la introducción en nuestro país de la nomenclatura de las ciencias.

Las voces procedentes de América, por su parte, conocen en Vicenté Salvá el mayor impulso lexicográfico hasta la fecha. Azorín Fernández, especialista en la presencia de americanismos en la obra de Salvá, reconoce que (2008:14):

Uno de los logros de mayor trascendencia que se pueden atribuir a Vicente Salvá es el haber abierto el camino a la entrada de los americanismos en los diccionarios monolingües del español. En efecto, al polifacético filólogo valenciano le corresponde el mérito de ser el primero que vio la necesidad de incorporar, de manera más representativa y sistemática, el léxico americano a los repertorios lexicográficos del español. La importancia de su labor no se debe juzgar tan sólo por el considerable acopio de americanismos que logró reunir en su Nuevo Diccionario de la Lengua Castellana (1846), sino que, por encima de ese indudable aporte, su contribución más decisiva fue el haber planteado de manera explícita, en el extenso Prólogo que precede a la obra, la necesidad de revisar el mapa geolingüístico del español con fines lexicográficos.

Gracias a la labor pionera de Salvá, el español de América dejará de ser una pincelada anecdótica en las páginas de nuestros diccionarios para convertirse no sólo en objetivo de la práctica diccionarística sino también en objeto de reflexión metalexicográfica.

La Real Academia Española dará cabida a los tecnicismos y a los americanismos en las últimas ediciones de la centuria o en las primeras del siglo XX (cfr. Azorín Fernández, 2008, Clavería Nadal, 2016, Garriga Escribano, 2001 y 2018 y Garriga Escribano, Iglesia Martín y Rodríguez, 2013).

En el caso de las voces técnicas, el repertorio de Gildo y Le Touzé se caracteriza por incluir muchos términos de la química (en su mayoría helenismos y latinismos muchas veces llegados a través del francés) que, si bien no se encuentran en el DRAE1852 - que no es por otro lado un diccionario de especialidad-, cuentan con tradición lexicográfica en diccionarios no académicos de influencia o ascendencia francesa, de manera que Núñez de Taboada, Salvá, Castro y Rossi, Domínguez o la editorial Gaspar y Roig recogen estas voces entre la macroestructura de sus repertorios ${ }^{16}$.

El siguiente cuadro muestra algunos ejemplos de la terminología química de Gildo y Le Touzé, su documentación anterior en repertorios extracadémicos ${ }^{17}$, la edición

\footnotetext{
${ }^{15}$ Melchor Manuel Núñez de Taboada es autor de un Dictionnaire français-espagnol et espagnol-français, París, Brunot-Labbé, 1812; Vicente Salvá del Nuevo diccionario francés-español y español-francés, París, Granier Hermanos, 1856, y Ramón Joaquín Domínguez compuso el Diccionario universal español-francés y francés-español, Madrid, imprenta de la Viuda de Jordán e hijos, 1845-1846, y el Diccionario de bolsillo, francés-español y español-francés, Madrid, Viuda de Jordán e hijos, 1846.

${ }^{16}$ Algunas de estas voces están documentadas también después de 1857-1859 en el Nuevo Suplemento al Diccionario Nacional o Gran Diccionario clásico de la lengua española de Ramón Joaquín Domínguez (Madrid, Imprenta y Librería Universal de los Sres. Crespo, Martín y Comp., 1869), en el Suplemento. Nuevo diccionario de la lengua castellana de Vicente Salvá (París, Garnier Hermanos, 1879), así como en repertorios lexicográficos de finales de la centuria o comienzos del XX.

${ }^{17}$ Hemos cotejado la información con los diccionarios no académicos del XIX publicados antes de 1857, a los que en la tabla hemos asignado un número por orden cronológico: 1- Melchor Manuel Núñez de Taboa-
} 
posterior del DRAE en la que entraron — en donde, con mucha frecuencia, están precedidos de la marca quím.- así como los casos en los que la Academia no los registra:

\begin{tabular}{|c|c|c|c|c|c|c|}
\hline & 1 & 2 & 3 & 4 & 5 & $D R A E$ \\
\hline Ácido citrico diáfano= acide citrique diaphane & $\bullet$ & & & $\bullet$ & • & 1869 \\
\hline Ácido oxálico $=$ acide oxalique & & & & & $\bullet$ & 1884 \\
\hline Ácido tártrico $=$ acide tartrique & & & & & $\cdot$ & 1884 \\
\hline Albúmina $=$ albumine & & & & • & $\cdot$ & 1869 \\
\hline Alcalimetro $=$ alcalimètre & & & & $\cdot$ & $\bullet$ & 1869 \\
\hline Amigdalina $=$ amygdaline & & & & $\cdot$ & $\bullet$ & 1899 \\
\hline Azafrán de metal=oxyde de fer & & & & & • & - \\
\hline Azul de Prusia=bleu de Prusse & & & $\bullet$ & $\cdot$ & $\bullet$ & 1869 \\
\hline Bicarbonato=bicarbonate & & & & & $\bullet$ & 1884 \\
\hline Bitartrato $=$ bitartrate & & & & $\bullet$ & $\bullet$ & 1884 (tartrato) \\
\hline Blanco de plata $=$ blanc d'argent & & & & & $\cdot$ & 1936-Hist. \\
\hline Blanco de plomo=blanc de céruse & & & & & $\bullet$ & 1936-Hist. \\
\hline Blanco de zinc=blanc de zinc & & & & & $\bullet$ & - \\
\hline Brucina $=$ brucine & & & & • & • & $\begin{array}{c}1936 \text { (desde } \\
1899 \text { brucita) }\end{array}$ \\
\hline Calomel=calomel & $\cdot$ & $\cdot$ & & $\cdot$ & $\cdot$ & $\begin{array}{c}1884 \text { (desde el } \\
\text { DLE-2014 calo- } \\
\text { melanos) }\end{array}$ \\
\hline Castorato $=$ castorate & & & & $\bullet$ & $\bullet$ & - \\
\hline Castorina $=$ castorine & & & & $\cdot$ & $\bullet$ & 1925 \\
\hline Cianato $=$ cyanate & & & & $\cdot$ & $\bullet$ & 1925 \\
\hline Clorato de potasa $=$ chlorate de potasse & & & & $\cdot$ & $\cdot$ & 1884 \\
\hline Cloroformo $=$ chlorophorme & & & $\bullet$ & $\cdot$ & $\bullet$ & 1869 \\
\hline Cromato $=$ chromate & & & & $\cdot$ & $\bullet$ & - \\
\hline Emetina $=$ emétine & & & & $\bullet$ & $\cdot$ & 1950 \\
\hline Ergotina $=$ ergotine & & & & • & $\bullet$ & 1899 \\
\hline Estricnina $=$ strychnine & & & & • & $\bullet$ & 1884 \\
\hline Estronciana $=$ strontiane & $\bullet$ & & & • & $\bullet$ & 1899 \\
\hline Hidriodato $=$ hydriodate & & & & • & • & - \\
\hline Hidroclorato $=$ hydro-chlorate & & & & • & • & 1899 (clorhidrato) \\
\hline Hidrosulfato=hydro-sulfate & & & & • & $\bullet$ & - \\
\hline Manteca de antimonio= beurre d'antimoine & & & & & $\bullet$ & - \\
\hline
\end{tabular}

da: Diccionario de la lengua castellana, París, Seguin, 1825; 2- Vicente Salvá: Nuevo diccionario de la lengua castellana, París, Vicente Salvá, 1846; 3- Adolfo de Castro y Rossi: Biblioteca universal. Gran diccionario de la lengua española, Madrid, Oficinas y establecimiento tipográfico del Semanario Pintoresco y de la Ilustración, 1852; 4- Ramón Joaquín Domínguez: Diccionario Nacional o Gran Diccionario clásico de la lengua española y Suplemento al Diccionario Nacional, Madrid-París, Establecimiento de Mellado, 1853 y 5- Gaspar y Roig: Biblioteca Ilustrada de Gaspar y Roig. Diccionario enciclopédico de la lengua española, Madrid, Imprenta y Librería de Gaspar y Roig, 1853 (tomo I) y 1855 (tomo II). También hemos consultado las obras bilingües de los autores anteriores y las ediciones del DRAE. Consultados a partir de: Real Academia Española (2001): Nuevo Tesoro Lexicográfico de la lengua española. Disponible en http://www.rae.es/recursos/diccionarios/diccionarios-anteriores-1726-1992/nuevo-tesoro-lexicografico [junio-julio 2018] y de la Biblioteca Virtual de la Filología Española, www.bvfe.es. 


\begin{tabular}{|c|c|c|c|c|c|}
\hline Molibdeno=molybdène & & & • & - & 1869 \\
\hline Niquel=nickel & $\bullet$ & $\bullet$ & & & 1884 \\
\hline Oximuriato $=$ oxymuriate & & & & $\cdot$ & \\
\hline Peróxido $=$ peroxyde & & & $\cdot$ & $\cdot$ & 1884 \\
\hline Pirolignito $=$ pyrolignite & & & $\bullet$ & $\cdot$ & - \\
\hline Potasio $=$ potassium & & & $\bullet$ & $\bullet$ & 1869 \\
\hline Protocloruro $=$ protochlorure & & & & $\cdot$ & 1884 (hasta 1992) \\
\hline Protóxido $=$ protoxyde & & & $\cdot$ & $\cdot$ & 1899 \\
\hline Prusiato $=$ prussiate & & & $\bullet$ & $\cdot$ & 1899 \\
\hline Sal marina $=$ sel marine & & $\bullet$ & & - & 1869 \\
\hline Sal de acederas $=$ sel d'oseille & & $\bullet$ & & & 1884 \\
\hline Sal de nitro $=$ sel de nitre & & & & - & 1925 \\
\hline Sal de Saturno=sel saturne & & • & & - & 1899 \\
\hline Sal de Glauber $=$ sel de Glauber & & $\bullet$ & & • & - \\
\hline Sal de Epson=sel d'Epson & & • & & - & - \\
\hline Sal de sosa $=$ sel de soude & & & & • & - \\
\hline Salicina $=$ salicine & & & - & $\cdot$ & 1899 \\
\hline Silicato $=$ silicate & & & $\bullet$ & $\cdot$ & 1884 \\
\hline Sulfuro $=$ sulfure & & & $\cdot$ & $\cdot$ & 1869 \\
\hline Tartrato $=$ tartrate & & & $\bullet$ & $\cdot$ & 1884 \\
\hline Verde gris $=$ vert-de-gris & & & & $\cdot$ & - \\
\hline Yodo $=$ iode & & & & $\cdot$ & 1869 \\
\hline Yoduro=iodure & & & & $\cdot$ & 1869 \\
\hline
\end{tabular}

Algo parecido ocurre con el corpus compuesto por nombres de animales, de plantas y los principios activos que se extraían de ellas, pues, de nuevo, las primeras documentaciones lexicográficas se encuentran en los diccionarios no académicos decimonónicos y, solo algunos años después y no siempre, en la Academia:

\begin{tabular}{|c|c|c|c|c|c|c|}
\hline & 1 & 2 & 3 & 4 & 5 & $D R A E$ \\
\hline Acebollado $=$ aux oignons ${ }^{18}$ & & & & - & & - \\
\hline Aceite de oliva $=$ huile d'olive & & & & & $\bullet$ & 1936 \\
\hline Aceite esencial=huile d'essence & & & & $\bullet$ & $\bullet$ & 1884 \\
\hline Aciano $=$ bluet & & & & $\bullet$ & $\bullet$ & 1884 \\
\hline Alazar $=$ cartame, safrand bâtard ${ }^{19}$ & & & & $\bullet$ & & - \\
\hline Alizarina $=$ alizarine & & & & $\bullet$ & $\bullet$ & 1927 \\
\hline Almendra bañada=dragée & & $\cdot$ & & & $\bullet$ & - \\
\hline $\begin{array}{l}\begin{array}{l}\text { Almendra garrapiñada=amandes } \\
\text { praliné }\end{array} \\
\text { à la } \\
\end{array}$ & & • & & & $\bullet$ & - \\
\hline Andrópogon=andropangon & & & & $\bullet$ & $\bullet$ & - \\
\hline Aristea $=$ aristée & & & & $\bullet$ & $\cdot$ & - \\
\hline
\end{tabular}

${ }^{18}$ Desde 1884 está en el DRAE, aunque con otra acepción: «que tiene cebolladura (daño que tienen algunas madeas, y que consiste en haberse desunido dos capas contiguas de las varias anuales que forman el tejido leñoso del árbol)».

${ }^{19}$ Elías Zerolo (Diccionario enciclopédico de la lengua castellana, París, Garnier hermanos, 1895) plantea que pueda tratarse de una confusión con alazor, que, según el Diccionario de Autoridades, «en las boticas le conocen como cártamo y su flor es la que comúnmente se llama azafrán romí o salvaje». 


\begin{tabular}{|c|c|c|c|c|c|c|}
\hline Arcanson $=$ arcanson & & & & $\bullet$ & $\cdot$ & - \\
\hline Avena carmelita $=$ avenette blonde & & & & $\bullet$ & $\cdot$ & - \\
\hline Azúcar blanco $=$ sucre $2^{e}$ qualité & & & $\bullet$ & & & 1899 \\
\hline Becacin $=$ becassine & & & & $\cdot$ & $\cdot$ & $\begin{array}{c}1927 \text { (becacina } \\
\text { galicismo por } \\
\text { becada) }\end{array}$ \\
\hline Bruconesia=broussonetie & & & & $\cdot$ & & - \\
\hline Catecú=cachou & & & & $\cdot$ & $\cdot$ & 1884 \\
\hline Cayeput $/$ cayeputo $=$ cajeput $^{20}$ & & & & $\bullet$ & $\cdot$ & $\begin{array}{c}1936 \text { (cayeputi } \\
\text { desde 1899) }\end{array}$ \\
\hline Ceramión $=$ céramion & & & & $\cdot$ & & - \\
\hline Clematita $=$ clématite & & & & $\bullet$ & & - \\
\hline Colombo $=$ colombo & & & & $\bullet$ & $\cdot$ & 1927 \\
\hline Creosota $=$ créosote & & & & - & $\cdot$ & 1884 \\
\hline Digitalina $=$ digitaline & & & & $\bullet$ & & 1899 \\
\hline Estafisagria $=$ stafysaigre & & & & & $\cdot$ & 1884 \\
\hline Galipodio $=$ galipot & $\bullet$ & & & $\cdot$ & $\cdot$ & $\begin{array}{c}1936 \text { (galipote, } \\
\text { galicismo) }\end{array}$ \\
\hline Goma guta= gomme gutte & & & & $\bullet$ & $\cdot$ & - \\
\hline Goma laca=gomme laque & & & & $\cdot$ & $\cdot$ & 1925 \\
\hline Gomero $=$ gommier $^{21}$ & & • & & & & - \\
\hline Guayaquina $=$ guyacine & & & & - & & - \\
\hline Gutapercha $=$ gutta-percha & & & & & $\cdot$ & 1869 \\
\hline Indigófero=indigofère & & & & - & $\cdot$ & - \\
\hline Indigotina $=$ indigotine & & & & $\cdot$ & $\cdot$ & $\begin{array}{c}1927 \text { (hasta } \\
1898, \text { indigo) }\end{array}$ \\
\hline Lana (en) barro=laine fine non filée & $\bullet$ & $\bullet$ & & $\bullet$ & $\cdot$ & 1869 \\
\hline Lana sucia =laine en suint & & & & & $\cdot$ & - \\
\hline Licopodio=lycopode & $\bullet$ & & & $\bullet$ & $\cdot$ & 1899 \\
\hline Malabatro = malabathrum & & & & & .22 & - \\
\hline Nafé $=n a f e ́$ & & & & $\bullet$ & & - \\
\hline Prímula $=$ primèvere & & & & & $\cdot$ & $\begin{array}{c}1936 \text { (primavera, } \\
\text { planta) }\end{array}$ \\
\hline Quilópsido $=$ chilopside & & & & $\cdot$ & & - \\
\hline Salep $=$ salep $^{23}$ & & $\cdot$ & & $\cdot$ & $\cdot$ & 1884 \\
\hline Santonina $=$ santonine & & & & $\cdot$ & $\cdot$ & 1899 \\
\hline
\end{tabular}

${ }^{20}$ Antes está documentado en Esteban de Terreros y Pando (Diccionario castellano con las voces y artes, Madrid, Ibarra, 1786).

${ }^{21}$ Como árbol de las Antillas está documentado en Esteban de Terreros y Pando (Diccionario castellano con las voces y artes, Madrid, Ibarra, 1787) y en Vicente Salvá. La Academia documenta en 1925 «perteneciente o relativo a la goma» $\mathrm{y}$ «Argent. El que explota la industria de la goma», en 1884 recoge «dícese de los vegetales de que se obtiene goma» y en 1992 «Amér. Merid. Árbol que produce goma».

${ }^{22}$ Antes que Gaspar y Roig, habían recogido esta forma John Minsheu (Vocabularium Hispanicum Latinum et Anglicum, Londres, Joanum Browne, 1617) y Esteban de Terreros y Pando (Diccionario castellano con las voces y artes, Madrid, Ibarra, 1787).

${ }^{23}$ La primera documentatación es de Esteban de Terreros y Pando (Diccionario castellano con las voces y artes, Madrid, Ibarra, 1788). 


\begin{tabular}{|c|c|c|c|c|}
\hline Semencontra $=$ semen-contra & & & $\bullet$ & 1899 \\
\hline Simaruba $=$ simarouba ${ }^{24}$ & & $\bullet$ & $\bullet$ & 1956 \\
\hline Solanina $=$ solanine & & & $\bullet$ & 1914 \\
\hline Tanino=tannin & & $\bullet$ & $\bullet$ & 1884 \\
\hline Trigo chamorro=blé touselle, sans barbes & & $\bullet$ & & 1884 \\
\hline Tuberosa $=$ tubéreuse ${ }^{25}$ & $\cdot$ & $\bullet$ & $\bullet$ & 1899 \\
\hline Yerba pajarera $=$ morgeline & & & $\bullet$ & - \\
\hline
\end{tabular}

Así mismo, estos repertorios ayudan a datar y a establecer las equivalencias de algunos términos propios del comercio y de la economía que entran en la lexicografía en estos momentos ${ }^{26}$ :

\begin{tabular}{|c|c|c|c|c|c|c|}
\hline & 1 & 2 & 3 & 4 & 5 & $D R A E$ \\
\hline Afianzador $=$ garant, caution & & - & & $\bullet$ & • & 1933 \\
\hline Agente de cambio = agent de change & & & & - & & 1884 \\
\hline Agiotar $=$ agioter $^{27}$ & • & & & $\cdot$ & & - \\
\hline Bolsin $=$ coulisse de la bourse & & & & & $\cdot$ & 1869 \\
\hline Bonificación=boni, bonification & & & & $\bullet$ & & 1914 \\
\hline Bono $=$ bon $^{28}$ & & & $\bullet$ & $\bullet$ & - & 1869 \\
\hline Caja de amortización= caisse d'amortisment & & & $\bullet$ & $\bullet$ & $\bullet$ & 1884 \\
\hline Comanditar $=$ commanditer & & & & $\bullet$ & & 1927 \\
\hline Deuda activa $=$ dette active & & $\bullet$ & & $\bullet$ & $\bullet$ & - \\
\hline Deuda pasiva $=$ dette passive & & $\bullet$ & & $\bullet$ & $\bullet$ & - \\
\hline Deuda pública $=$ dette publique & & $\bullet$ & & $\bullet$ & $\bullet$ & 1869 \\
\hline Empaquetador $=$ emballeur ${ }^{29}$ & & $\bullet$ & & $\bullet$ & & 1884 \\
\hline Endosador $=$ endosseur $^{30}$ & & - & & & $\bullet$ & $\begin{array}{l}\text { Ha preferido la } \\
\text { forma endosante }\end{array}$ \\
\hline${\text { Estagnación }=\text { stagnation }^{31}}^{31}$ & & $\bullet$ & & $\cdot$ & $\bullet$ & $\begin{array}{l}\text { Ha preferido la } \\
\text { forma estancación }\end{array}$ \\
\hline Expedidor $=$ expéditeur & & & & $\bullet$ & & 1899 \\
\hline Financiero=financier & & $\bullet$ & & & & 1884 \\
\hline Liquidador $=$ liquidateur & & & & $\bullet$ & • & 1925 \\
\hline
\end{tabular}

${ }^{24}$ La primera documentación es de Esteban de Terreros y Pando (Diccionario castellano con las voces y artes, Madrid, Ibarra, 1788).

${ }^{25}$ También documentan la forma con la acepción «flor, jacinto oriental, amiga de noche, vara de jesé» Francisco Sobrino (Diccionario nuevo de las lenguas española y francesa, Bruselas, Francisco Foppens, 1705) y Esteban de Terreros y Pando (Diccionario castellano con las voces y artes, Madrid, Ibarra, 1788).

${ }^{26}$ En la centuria anterior empezaron a emplearse muchos términos de la economía y del comercio que, aunque no eran nuevos, conocen un mayor auge y uso (Garriga Escribano, 1996 y Gómez de Enterría, 1996).

${ }^{27}$ Las formas agiotage y agiotador están en el DRAE desde las ediciones de 1803 y 1817 , respectivamente.

${ }^{28}$ Desde Autoridades está como variante de bueno.

${ }^{29}$ Antes está documentado en Francisco Sobrino (Diccionario nuevo de las lenguas española y francesa, Bruselas, Francisco Foppens, 1705) y Esteban de Terreros y Pando (Diccionario castellano con las voces y artes, Madrid, Ibarra, 1787).

${ }^{30}$ La primera documentación es de Esteban de Terreros y Pando (Diccionario castellano con las voces y artes, Madrid, Ibarra, 1787).

${ }^{31}$ Lo recoge también Núñez de Taboada, pero con el sentido de «detención de las aguas que no corren o de los humores que no circulan». El primero que hace alusión a la estaganación aplicada a los negocios mercantiles es Salvá. 


\begin{tabular}{|l|c|c|c|c|c|c|}
\hline Manufacturar=manufacturer & $\bullet$ & $\bullet$ & & $\bullet$ & $\bullet$ & 1925 \\
\hline Póliza de cargamento= pólice de chargment & & $\bullet$ & & & $\bullet$ & - \\
\hline Póliza de fletamiento= pólice d'affrétement & & $\bullet$ & & & $\bullet$ & - \\
\hline Póliza de seguro= pólice d'assurance & & $\bullet$ & & & $\bullet$ & - \\
\hline Reembarque=réembarquement & & $\bullet$ & & & $\bullet$ & 1925 \\
\hline Reembolsable=remboursable & & & & $\bullet$ & & 1925 \\
\hline Remolcador $=$ remorqueur & & & & $\bullet$ & & 1899 \\
\hline (Sala) sindical=(chambre) syndicale ${ }^{32}$ & & $\bullet$ & & $\bullet$ & $\bullet$ & 1899 \\
\hline Sucursal $=$ sucursale & & & & & $\bullet$ & 1869 \\
\hline
\end{tabular}

También tienen su primera documentación lexicográfica en los diccionarios del español decimonónico algunos nombres de tejidos y otras voces misceláneas:

\begin{tabular}{|c|c|c|c|c|c|c|}
\hline & 1 & 2 & 3 & 4 & 5 & $D R A E$ \\
\hline Abeadores $=$ lisses $^{33}$ & & & $\bullet$ & $\bullet$ & $\bullet$ & - \\
\hline Antolares $=$ entre-deux ${ }^{34}$ & & & $\bullet$ & & $\cdot$ & $\begin{array}{c}\text { 1933-Hist. (anto- } \\
\text { las, ¿por error?) } \\
1927 \text { (hasta } \\
1989, \text { entredós) }\end{array}$ \\
\hline Chali $=$ chaly & & & & $\cdot$ & $\cdot$ & - \\
\hline Guinga/guingampa $=$ guingamp & & & & $\cdot$ & $\cdot$ & 1869 \\
\hline Nipis = toile fabriquée aux îles Philippines & & & & & $\bullet$ & 1844 \\
\hline
\end{tabular}

\begin{tabular}{|l|c|c|c|c|c|c|}
\hline & 1 & 2 & 3 & 4 & 5 & DRAE \\
\hline Abitanis=abitanis $^{35}$ & & & & $\bullet$ & & - \\
\hline Azul cobalto=bleu de cobalt & & & & $\bullet$ & $\bullet$ & - \\
\hline Azul mineral=bleu minéral & & & & $\bullet$ & & 1869 \\
\hline
\end{tabular}

${ }^{32}$ Antes está documentada en Esteban de Terreros y Pando (Diccionario castellano con las voces y artes, Madrid, Ibarra, 1788).

${ }^{33}$ La forma abeadores se documenta por primera vez en Esteban de Terreros y Pando (Diccionario castellano con las voces y artes, Madrid, Ibarra, 1786) como «en los telares de terciopelo una especie de lizos que se van previniendo para rejir la tela; y su número se varía según el cuerpo que se quiere dar al terciopelo. Fr. Lisses pour la toile», quien remite al Espectáculo de la naturaleza del abate Noël-Antonio Pluche (tomo 12), texto que tradujo el jesuita y que fue el germen de su Diccionario (Alvar Ezquerra, 1987b, Azorín Fernández, 2006). De él lo debieron tomar los lexicógrafos decimonónicos (Castro y Rossi, Domínguez, Gaspar y Roig, Salvá, Zerolo, Alemany y Bolufer y Rodróguez Navas), María Moliner o el Diccionario enciclopédico Espasa, entre otros.

${ }^{34}$ Castro y Rossi, primero de nuestros lexicógrafos en recogerla, remite a Esteban Pichardo y Tapia (1836) y dice ser voz cubana que significa «tira de punto o lienzo fino bordada para añadirla al vestido por ambas orillas, en lo cual se diferencia de la punta que deja una libre». Esteban Rodríguez Herrera (1953) afirma que «al presente está fuera de todo uso esta palabra»; de la misma manera, Esteban Rodríguez Herrera (1958), aunque copia la definición de Pichardo, sostiene que «actualmente no conocemos esta palabra en Cuba, ni de oídas. Suponemos que sea lo que las costureras laman entredós, o embutido en Arg. Méx., Urug., y Venez.». En La Voz de México (9-VI-1897) se dice que los antolares son «las bandas o tiras de tul, aun cuando en sus orillas se encuentren hilos de materia distinta».

Gaspar y Roig recoge también la voz entolar y el DRAE, desde 1914, como «pasar de un tul a otro las flores de un encaje».

${ }^{35}$ Según Álvaro Alonso Barba (1639) abitanis «en lengua Lipe quiere decir mina de oro». Es el nombre de la más rica mina de oro del Perú. 


\begin{tabular}{|c|c|c|c|c|c|}
\hline Azul ultramarino $=$ bleu outre-mer & & & $\cdot$ & • & $\begin{array}{l}1869(\text { de } \\
\text { ultramar })\end{array}$ \\
\hline Barco de vapor=bateau, paquebot à vapeur & $\bullet$ & $\bullet$ & & $\bullet$ & - \\
\hline Barco cubierto=bâtiment ponté & & $\bullet$ & & $\bullet$ & - \\
\hline Blanco de ballena $=$ blanc de baleine & & & & $\bullet$ & 1936-Hist. \\
\hline Buque de vapor= bateau, paquebot à vapeur & & & $\bullet$ & & 1869 \\
\hline Buque de guerra=navire de guerre & & - & $\bullet$ & & 1869 \\
\hline Buque mercante $=$ navire marchand & & - & $\bullet$ & & 1869 \\
\hline Bocoy $=$ boucaut & & & $\bullet$ & $\bullet$ & 1869 \\
\hline Clipsopompo= clysopompe ${ }^{36}$ & & • & $\bullet$ & $\bullet$ & - \\
\hline Defectuosidad=défaut & & & $\bullet$ & & $\begin{array}{l}\text { La RAE prefirió } \\
\text { defecto }\end{array}$ \\
\hline Dulcera $=$ compotier & & & & $\bullet$ & 1869 \\
\hline $\begin{array}{l}\text { Fosforera }=\text { porte-allemettes, boîte à allu- } \\
\text { mettes }\end{array}$ & & & & $\bullet$ & 1869 \\
\hline Gantelete $=$ gantelet & & & $\bullet$ & & $\begin{array}{l}\text { La RAE prefirió } \\
\text { guantelete (1803) }\end{array}$ \\
\hline Locomotiva $=$ locomotive & $\cdot$ & & & $\bullet$ & $\begin{array}{c}\text { La RAE prefirió } \\
\text { locomotora } \\
(1869) \text { y locomo- } \\
\text { triz (1884) }\end{array}$ \\
\hline Locomotora $=$ locomotiva, locomotive & & & & $\bullet$ & $\begin{array}{c}\text { La RAE prefirió } \\
\text { locomotora } \\
(1869) \text { y locomo- } \\
\text { triz (1884) }\end{array}$ \\
\hline Mantequillera $=$ beurrier & $\bullet$ & & & $\bullet$ & $\begin{array}{l}\text { 1925, Amér. } \\
\text { mantequera }\end{array}$ \\
\hline Odontina $=$ odontine & & & $\bullet$ & $\bullet$ & - \\
\hline Pañolón $=$ châle & $\bullet$ & & $\bullet$ & $\bullet$ & 1884 \\
\hline Papel secante= papier buvard & $\bullet$ & & & $\bullet$ & 1899 \\
\hline $\begin{array}{l}\text { Redoblante = tambour à longue caisse pour } \\
\text { la musique militaire }\end{array}$ & & & $\bullet$ & $\bullet$ & 1884 \\
\hline $\begin{array}{l}\text { Sombrero chambergo=chapeau } \grave{a} \text { bords } \\
\text { rabattus }\end{array}$ & & & $\bullet$ & & 1884 \\
\hline $\begin{array}{l}\text { Tinta simpática=encre sympathique (ou) à } \\
\text { copier }\end{array}$ & $\bullet$ & & & $\bullet$ & 1869 \\
\hline
\end{tabular}

Otras veces, en cambio, las voces encuentran, dadas las relaciones filogenéticas entre estos diccionarios, documentaciones lexicográficas en los repertorios no académicos de finales del siglo XIX o primeras décadas del siglo XX, esto es, en Elías Zerolo, en Miguel de Toro y Gómez, en Aniceto Pagés, en José Alemany y Bolufer o en Manuel Rodríguez Navas ${ }^{37}$ :

${ }^{36}$ La variante registrada en Castro y Rossi, Domínguez y Gaspar y Roig es clisobomba.

37 1-Diccionario enciclopédico de la lengua castellana de Elías Zerolo (París, Garnier Hermanos, 1895). 2Nuevo diccionario enciclopédico ilustrado de la lengua castellana de Miguel de Toro y Gómez (ParísMadrid, Librería Armand Colin-Hernando y Cía, 1901). 3-Gran diccionario de la lengua castellana de Aniceto de Pagés (Madrid, sucesores de Rivadeneyra, 1904, tomo I; Barcelona, Pedro Ortega, 1904, tomo 


\begin{tabular}{|c|c|c|c|c|c|c|}
\hline & 1 & 2 & 3 & 4 & 5 & $D R A E$ \\
\hline Aceite de abeto=huile de pin & & & • & & & $\begin{array}{c}1914 \\
\text { (desde Autorida- } \\
\text { des, abetinote) }\end{array}$ \\
\hline Aceite de ballena=huile de baleine & & & $\bullet$ & & & 1914 \\
\hline Blanco de España=blanc d'Espagne & $\bullet$ & & & & & 1936-Hist. \\
\hline Brócoli=brocoli, chaux-fleurs violets & • & • & & & & $\begin{array}{c}2014 \\
\text { (desde } \text { Autorida- } \\
\text { des, bróculi) }\end{array}$ \\
\hline Colofana $=$ colophane & & & & • & • & $\begin{array}{c}\text { La RAE prefirió } \\
\text { colofania }\end{array}$ \\
\hline Contravalor $=$ contre-valeur & & & & $\bullet$ & & 1984 \\
\hline Fular=foulard & & & & $\bullet$ & $\bullet$ & 1927 \\
\hline Guata $=$ ouate & $\cdot$ & & & $\bullet$ & $\cdot$ & 1925 \\
\hline Huata=ouate & & & & $\cdot$ & $\cdot$ & - \\
\hline Hydroferrocinatao = hydro-ferro-cyanate & & & & • & • & - \\
\hline Macarela $=$ maquereau & & & & $\cdot$ & $\bullet$ & - \\
\hline Paralización $=$ paralysie, stagnation & & & & & $\bullet$ & 1925 \\
\hline Quimáfila $=$ chimafile & $\bullet$ & & & & & - \\
\hline Raspalenguas $=$ râpe-langue & $\bullet$ & & & - & & - \\
\hline
\end{tabular}

Finalmente, el corpus recogido por Gildo y Le Touzé permite, por un lado, manifestar la vigencia y la utilidad de los términos que entraron en el diccionario académico en la primera mitad del siglo XIX, y por otro, demostrar que este Diccionario es una buena fuente para datar algunos neologismos que entraron en la segunda mitad y que no conocen presencia lexicográfica anterior:

Ediciones $D R A E$

1803 agio, agiotador, agiotage, agiotista, bedelio, cedente, hidrómetro, mamey, manufactura, marchante, natrón, naviero, potasa, puzolana, requinto

1817 almacenage, areómetro, belemnita, cabotage, capitalista, carromatero, esquenanto, prestamista (antes prestador), quermes, zinc

1822 ácido sulfúrico, capitalizar, comitente, decomisar, decomiso, déficit, embalaje, óxido, tormentilla

1832 ácido muriático, ácido nítrico, mostacilla, poderdante

1837 contabilidad, empresario

$1843 \quad$ justiprecio, pezpalo

1852 carbonato, comanditario, comandita, cotización, ferrocarril, nitrato, sílice, solvencia, sulfato

Ediciones DRAE

Voces

II; Barcelona, Fomento Comercial de Libro, 1914, tomo III, 1925, tomo IV y 1931, tomo V). 4-Diccionario de la lengua española de José Alemany y Bolufer (Barcelona, Ramón Sopena, 1917). 5-Diccionario general y técnico hispano-americano de Manuel Rodríguez Navas y Carrasco (Madrid, Cultura Hispanoamericana 1918). Cfr. Real Academia Española (2001). 
agua de colonia, buque a la carga, buque de vela, papel pintado, trigo trementino

1884 aceite de hígado de bacalao, almendra amarga, azul turquí, chamberguillas ${ }^{38}$, plato sopero, rail (antes riel), té negro, té verde, tinta de imprenta, trigo rubión, trigo sarracénico papel de luto, quebrantapiedras, té perla plato hondo, plato llano tinta (de) China

Y por supuesto se pueden extraer de este corpus voces neológicas que no han entrado (y muchas de ellas, seguramente, ya ni entren) en el diccionario académico o bien porque la Academia ha preferido otras variantes de tradición hispana, o bien porque son diminutivos, o bien porque son voces especializadas:
Aborlado $(=$ a côtes $)$, acerito $\left(=\right.$ pelotte à aiguilles $\left.{ }^{39}\right)$, acta de abandono $(=$ acte d'abandon), afianzadores de goma (=des élastiques), alemeta (=filasse), alenzón (=point d'Alençon), amarillo de cromo (=jaune de chrome), amarillo de Nápoles (=jaune de Naples), amarillo de plomo (=jaune de plomb), anas- cotada (=imitation d'anascote), anchaguantes (=baguette à gants), andropa- gon (=nard, espèce de lavande), arbitragista (=arbitragiste), atesto $\left(=\right.$ témoignage attestation $\left.{ }^{40}\right)$, calamarín $(=$ petit calmar $)$, cameloncillo (=imitation de camelot $\left.^{41}\right)$, calzapollos (=calzapollos, chaussure d'Amérique), compromisar (=faire un compromis), copiacartas (=presse à copier), cuerci- trón (=quercitron), derecho de corretaje (=droit de courtage), derecho adi- cional (=droit additionel), derecho de puertas (=droit d'octroi), encarmena- dor $\left(=\right.$ déméloir $\left.^{42}\right)$, enfardelage $\left(=\right.$ emballage $\left.{ }^{43}\right)$, germandrina $(=$ germandrée fleur $\left.^{44}\right)$, letrita (=petit effet, broche), negro de huesos (=noir d'os), negro de imprenta (=noir de fumée), palanganita (=petite cuvette), pepel vidrio (=papier de verre), pildorera (=boîte à pilules), pomito (=petit flacon, petit pot), portalicores (=petite étagère en bois servant à porter les flacons de li- queurs), portamoneda (=porte-monnaie), portapluma (=porte-plume), porta- vaso (=soucoupe à verre), portavinagreras (v. angarillas), protosulfato (=protosulfate), pruebalicores (=pèse-liqueurs), pult de seda (=poult de soie, gorgoran), québulo (=kebule, fruit), quefequilito (=keffekilite, minéra $\left.l^{45}\right)$,

\footnotetext{
${ }^{38}$ Desde el DRAE-1884 aparece como diminutivo de chamberga «And. género de cinta de seda muy angosta», que podría proceder de chamberga (de C. Schömberg, 1601-1656, mariscal de Francia que introdujo la moda en el uniforme durante la guerra de Cataluña hacia 1650) «se aplica también a algunas prendas de este uniforme». La equivalencia francesa faveur-favor refiere a la cinta dada a un caballero por su dama ( $D L E$ : «cinta, flor $\mathrm{u}$ otra cosa semejante dada por una dama a un caballero, y que en las fiestas públicas llevaba este en el sombrero o en el brazo» por la ayuda o apoyo que le brindaba la dama).

${ }^{39}$ Desde Autoridades se encuentra acerico.

${ }^{40}$ Desde Autoridades se encuentra atestación.

${ }^{41}$ En el DRAE-1936 histórico, y sin más tradición lexicográfica, se encuentra camelotillo.

${ }^{42}$ Desde Autoridades se encuentra escarmenador.

${ }^{43}$ Desde DRAE-1822 se encuentra embalaje.

${ }^{44}$ Desde DRAE-1822 se opta por la variante camedrio $<$ chamaedrys.

${ }^{45}$ Lo recoge Ramón Joaquín Domínguez en su Diccionario universal francés-español (Madrid, R. J. Domínguez, 1845, tomo II)
} 
quieselguro (=kieselgurh, minéral $\left.{ }^{46}\right)$, quieselspato (=quiselspath, minéral $\left.{ }^{47}\right)$, ruanería (=rouennerie, étoffes), sacocola (=colle-chair), salsomosa $\left(=\right.$ soude $\left.^{48}\right)$, té imperial (=thé impérial), té peco (=thé peko), trigo rojo ${ }^{49}\left(=\right.$ blé $^{2}$ roux), valenciana (=valencienne, dentelle), verde de París (=vert de Paris), yerba de la celada (=toque des Alpes), yerba de san Pablo (=primèvere).

En cuanto a la procedencia del léxico, el corpus de Gildo y Le Touzé recoge voces que obedecen a procesos de terminologización, extranjerismos, cultismos (muchos de ellos, como se ha visto, llegados a través del francés) y voces creadas a partir de los procesos morfológicos de formación de palabras (cfr. Arntz y Picht, 1995, Cabré, 1993, Gutiérrez Rodilla, 1998 y Rondeau, 1983).

La especialización o terminologización que en determinados contextos adquieren muchas de las voces generales recogidas en el Diccionario se indica dentro del artículo lexicográfico a través de unidades pluriverbales de diferente tipo (locuciones, segmentos sintácticos, colocaciones, ejemplos). Es lo que ocurre, por ejemplo, con abandonar un negocio, su derecho, sus pretensiones; abaratar, esta mercancía abarata, abrir una cuenta, crédito, los libros; ajustar una cuenta, una diferencia, el precio, una operación; alza de fondos públicos, estar en alza, sostenerse en alza, jugar al alza, jugador al alza; caja de amortización, hipotecaria, de depósitos y consignaciones, de ingresos, de descuento, efectivo en caja, descubierto en caja; casa de comercio, de primer orden, bien aparroquiada, de moneda; declaración de la aduana, de los géneros; gastos de aduana, de acarreo, judiciarios, adicionales, deducidos, de protesta, de escala, menudos; gobierno, para su gobierno; letra de cambio, a largo plazo, a corto plazo, sellada, capital de una letra, importe de la letra, giro de letras, cobrar una letra, endosar una letra; llevar a la cuenta, al crédito, de conformidad, a efecto, escrito, adelante un negocio; mérito, se reduce el mérito de esta...; perjuicio, daños y perjuicios, $1 \%$ de perjuicio; reconocimiento de montepio, señal de reconocimiento; título al portador, nominal o personal, de crédito, flotante, clasificado, emisión de títulos.

Los préstamos léxicos, por su parte, proceden, mayoritariamente de las lenguas clásicas (sobre todo en los términos que refieren a voces químicas y plantas) y, teniendo en cuenta la influencia y la presencia del país vecino en esta centuria, del francés, que a su vez pueden ser directos o indirectos, adaptados o calcos.

\begin{tabular}{|c|c|}
\hline Helenismos & aciano, creosota, protóxido (a través del inglés), \\
\hline Latinismos & $\begin{array}{l}\text { ácido, albúmina, amigdalina, locomotora, potasio (procedente del } \\
\text { inglés potass }+ \text { ium), prímula, semencontra, sucursal, tuberosa }\end{array}$ \\
\hline $\begin{array}{l}\text { Formas greco- } \\
\text { latinas }\end{array}$ & $\begin{array}{l}\text { andrópogon, clisobomba, colofana, cuercitrón, emetina, estafisagria, } \\
\text { germandrina, hidroferrocinato, licopodio, malabatro, molibdeno, } \\
\text { protosulfato }\end{array}$ \\
\hline Galicismos & aceite de ballena, agiotar (procedente del italiano aggio), alemet \\
\hline
\end{tabular}

\footnotetext{
${ }^{46}$ Lo recoge Ramón Joaquín Domínguez en su Diccionario universal francés-español (Madrid, R. J. Domínguez, 1845, tomo II).

${ }^{47}$ Lo recoge Ramón Joaquín Domínguez en su Diccionario universal francés-español (Madrid, R. J. Domínguez, 1845, tomo II).

${ }^{48}$ Desde Autoridades se encuentra soda.

${ }^{49}$ Desde DRAE-1884 se encuentra como variante trigo rubión.
} 
Alenzón, aristea, arcanson, azul cobalto, azul de Prusia, azul mineral, blanco de ballena, blanco de España, blanco de zinc, bocoy (de origen germano), buque de guerra, buque de vapor, castorato, bitartrato, bruconesia, chali, clematita, comanditar, cromato, deuda activa, deuda pasiva, deuda pública, ergotina, financiero, gantelete, guata/huata, hidriodato, hidroclorato, hidrosulfato, indigofero, pirolignito, póliza de seguro, protocloruro, pult, sal de nitro, sal de saturno, sal marina, salep (procedente del árabe), simaruba (procedente del caribe), tanino, tinta simpática, yodo

Otras lenguas abitanis (americanismo), alazor (árabe), brócoli (italiano), catecú (lusismo procedente del maratí), cayeputi (malayo), colombo (ceilanés), estronciana (anglicismo), guinga (lusismo de origen malayo), gutapercha (anglicismo procedente del malayo gata perca), macarela (americanismo), nipis (tagalo), níquel (germanismo), peróxido (anglicismo), quieselguro (germanismo), quimáfila (americanismo)

Finalmente, entre los procesos morfológicos de formación de palabras encontramos voces derivadas y compuestas, que pueden, a su vez, ser sintagmáticas o no, tener bases compositivas cultas o ser mixtas en cuanto a sus orígenes lingüísticos:

acebollado, acerito, afianzador, agua de colonia, agente de cambio, alcalimetro, almendra bañada, anchaguantes, avena carmelita, bolsín, bonificación, brucita, calomelanos, castorina, cianato, clorato, cloroformo, copia de amortización, copiacartas, defectuosidad, derecho adicional, digitalina, dulcera, endosador, estricnina, fosforera, galipodio, goma laca, gomero, indigotina, letrita, liquidador, mantequillera, manufacturar, mostacilla, oximuriato, palanganita, pañolón, papel de luto, papel pintado, papel secante, plato hondo, plato sopero, portalicores, protocloruro, prusiato, pult de seda, quebrantapiedras, redoblante, reembarque, reembolsable, ruanería, sal de acederas, salcina, santónica, silicato, sombrero chambergo, sulfuro, té verde, té negro, tinta de imprenta, trigo trementino, yoduro, valenciana ...

\section{REFLEXIONES FINALES}

La obra de Gildo y Le Touzé es una buena muestra de los manuales que se compusieron en el siglo XIX para satisfacer las necesidades que Europa había creado fruto de las transacciones mercantiles con el resto del continente y con las colonias. La rentabilidad económica que estos manuales suponían para autores y editores, sobre todo a partir de la apertura de centros de formación especializados, hizo que se multiplicasen sus publicaciones y sus beneficios.

El contenido de estos textos es fundamentalmente práctico: la correspondencia y el repertorio léxico solo tienen como objetivo ayudar a los comerciantes en sus tareas diarias. La primera, pese a su tradición y su escasa originalidad, pone de manifiesto que seguía resultando un material útil para la enseñanza del español comercial, para conocer los rasgos y estrategias de una tipología textual fundamental para el desarrollo de las transacciones comerciales.

El Diccionario, por su parte, recoge de forma sencilla y sucinta el léxico habitual en el comercio, y, aunque la ausencia de definiciones limite las conclusiones de este estudio, 
las voces de la química, las voces especializadas o los nombres de los artículos con los que se mercadeaba (plantas, animales, moda, costumbres) ofrecen, desde la lexicografía menor, un panorama muy interesante sobre la labor diccionarística del siglo XIX.

En primer lugar, porque el corpus de Gildo y Le Touzé enfatiza, una vez más, la deuda con los lexicógrafos no académicos decimonónicos (Salvá, Domínguez, Gaspar y Roig, fundamentalmente, quienes con la introducción de voces nuevas, no solo de tecnicismos, marcaron el futuro de la lexicografía española), así como con el completísimo Diccionario de Esteban de Terreros. De ellos afirma Seco (1987a: 150) que «aportan a la lexicografía española vigente una incorporación más abierta del léxico actual, apelando más al uso del pueblo que al uso literario. Es muy valiosa - y no tomada en serio hasta muchos decenios después - la determinación de Salvá de dar entrada plena al español de América. Siguiendo el ejemplo del gran Terreros en el siglo anterior, se decide dar paso al tecnicismo de las ciencias, de las artes y de los oficios, y, a imitación de la corriente lexicográfica francesa, surge el ideal del diccionario acumulativo (ideal aún hoy muy vivo en la opinión vulgar), de donde nace la aclimatación entre nosotros, de la mano de Domínguez, del género diccionario enciclopédico, que tanta boga alcanzará a partir de los últimos años del siglo y que hoy continúa en plena pujanza».

En segundo lugar, este corpus subraya la labor lexicográfica de la Academia en la segunda mitad de la centuria, porque, aunque desde 1803 la Academia se decidiera por admitir numerosos neologismos y ampliar el lemario del DRAE (de lo que también queda constancia en el Diccionairo de Gildo y Le Touzé: agio, bedelio, manufactura, marchante, naviero, prestamista, zinc, ácido muriático, contabilidad, justiprecio), las ediciones de 1869 , de 1884 y de 1899 supusieron «un considerable aumento y una intensa revisión tanto de la macroestructura como de la microestructura. Las tres últimas ediciones de la centuria van acompañadas de un enorme avance no solo en la concepción lexicológica sino también en la metodología lexicográfica y todo ello reporta variaciones en el tratamiento de la innovación léxica» (Clavería Nadal, 2016: 133). En el mismo sentido, destaca su deseo de continuar mejorando y desarrollando el repertorio lexicográfico en la centuria siguiente con voces que, dada la documentación, debían tener un uso frecuente en español: el $D R A E-1925$ recoge por primera vez varios términos de la economía y el comercio; el DRAE histórico documenta blanco de ballena, blanco de plata o blanco de plomo; el DRAE-1956, simaruba y el DRAE-1984, contravalor, plato hondo o plato llano.

El Diccionario de Gildo y Le Touzé evidencia también los procedimientos utilizados para la formación de palabras nuevas, entre los que destacan, sin duda alguna, la adaptación y los calcos del francés. La lengua del país vecino es la que ejerce una mayor influencia a lo largo de toda la centuria y de ella se toman voces de la vida social, de la moda, de la vivienda, de la gastronomía, de las actividades militares, de las actividades comerciales y bancarias y de la vida política y administrativa, voces que, con mayor o menor fortuna, son sometidas a un proceso de aclimatación fónica y morfológica (Álvarez de Miranda, 2004, Colón, 2002, Lapesa, 1991). «Cuando toda Europa tenía a gala seguir las modas de la corte de Versalles, era imposible frenar el auge del galicismo, considerado como rasgo de buen tono; y otro tanto siguió ocurriendo luego, 
como consecuencia del influjo francés en los más diversos órdenes de la vida» (Lapesa, 1991: 454).

De la misma manera, este corpus ejemplifica la utilización, sobre todo en la ciencia y en la técnica, de componentes griegos y latinos en la formación de voces nuevas, así como la entrada de americanismos, de anglicismos y de palabras llegadas del tagalo, del malayo o del ceilanés, y que no hacen sino reflejar la difusión y el intercambio entre naciones que conlleva el comercio. Además, esta recopilación léxica testimonia voces neológicas y los procedimientos que han servido para formarlas (acerito, anchaguantes, calzapollos, derecho de corretaje, palanganita, portavinagreras, protosulfato, ruanería, té peco, verde de París, yerba de San Pablo).

$\mathrm{Y}$, finalmente, resulta interesante el método que utilizan para enseñar cómo muchas voces o acepciones de la lengua general se convierten en tecnicismos en el lenguaje comercial en determinados contextos o usos, lo que consiguen con la introducción en el artículo lexicográfico de locuciones, colocaciones o ejemplos que ayudarían en la traducción entre las dos lenguas (abandonar un negocio, descubierto en caja,jugador al alza, casa de primer orden, gastos de acarreo, llevar adelante un negocio, título flotante).

El Diccionario comercial francés-español de Domingo Gildo y Charles Le Touzé, aunque repita y calque muchos de los rasgos de otros diccionarios, nos permite apreciar el valor de los vocabularios comerciales menores como fuente para el conocimiento y la datación lexicográfica a partir del tratamiento que negociantes, banqueros y comerciantes dieron a estos términos.

\section{REFERENCIAS BIBLIOGRÁFICAS}

Alonso BARBA, Á. (1639): Arte de los metales, Madrid, Viuda de Manuel Fernández.

ALVAR EZQUERRA, M. (1987a): «La recepción de americanismos en los diccionarios generales de la lengua», en H. López Morales y M. Vaquero, coords., Actas del I Congreso Internacional sobre el español de América, San Juan, Academia Puertorriqueña de la Lengua Española, pp. 209-218.

AlVAR EZQUeRRA, M. (1987b): «Presentación», en E. Terreros, Diccionario castellano con las voces de ciencias y artes y sus correspondencias en las tres lenguas francesa, latina e italiana, ed. facs., Madrid, Arco/Libros, pp. 5-26.

Alvar EzQuerra, M. Biblioteca Virtual de la Filología Española. Disponible en: www.bvfe.es.

Álvarez de Miranda, P. (2004): «El léxico español, desde el siglo XVIII hasta hoy», en R. Cano, coord., Historia de la lengua española, Barcelona, Ariel, pp. 1037-1064.

ANGLADA, E. (1997-98): «Traducción y diccionario. Algunos neologismos de la química en el Nuevo diccionario francés-español (1805) de A. de Capmany», Revista de Lexicografia, IV, pp. 31-47.

ARNTZ, R. y H. PICHT (1995): Introducción a la terminología, Madrid, Fundación Germán Sánchez Ruipérez.

AZORÍN FERNÁNDEZ, D. (2002): «El léxico de especialidad en el Nuevo diccionario de la lengua castellana (1846) de Vicente Salvá», en A. Bernabé Pajares et al., eds., 
Presente y futuro de la lingüistica en España. La Sociedad de Lingüística, 30 años después, Madrid, Sociedad Española de Lingüística, vol. II, pp. 329-337.

AZORÍN FERNÁNDEZ, D. (2002-2004): «La dimensión diacrónica en el Nuevo diccionario de la lengua castellana (1846) de Vicente Salvá», Archivo de Filología Aragonesa, 59-60, pp. 197-210.

AZORÍN FERNÁNDEZ, D. (2003): «El léxico americano en el Nuevo diccionario de la lengua castellana (1846)», en F. Sánchez Miret, coord., Actas del XXIII Congreso Internacional de Lingüística y Filología Románica, Tubinga, Max Niemeyer Verlag, pp. 91-103.

AZORÍN FERNÁNDEZ, D. (2003): «Neologismos incorporados por Salvá en el Nuevo diccionario de la lengua castellana», Estudios de lingüistica: ELUA, 17, pp. 107-140.

AzORÍn FERNÁNDEZ, D. (2006): «El Espectáculo de la Naturaleza (1753-1755) traducido por Terreros y Pando como fuente de su Diccionario castellano con las voces de Ciencias y Artes (1786-1793)», en J. L. Girón Alconchel, ed., Actas del VI Congreso Internacional de Historia de la lengua española, Madrid, Arco/Libros, pp. 1253-1268.

AZORÍN FERNÁNDEZ, D. (2007): «La incorporación de neologismos en los diccionarios del español del siglo XIX: criterios y realizaciones», en M. Campos Souto et al., eds., El nuevo léxico, A Coruña, Anejos de Revista de Lexicografía, pp. 53-66.

AZORÍn FERNÁNDEZ, D. (2008): «Para la historia de los americanismos léxicos en los diccionarios del español», Revista de investigación lingüística, 11, 1, pp. 13-43.

AZORÍN FERNÁNDEZ, D. (2012): «Contribución a la historia de los términos en los diccionarios generales del español: Salvá y la Academia Española ante el problema de los tecnicismos», en F. Rodríguez González, coord., Estudios de lingüística española: Homenaje a Manuel Seco, Alicante, Universidad de Alicante, pp. 91-118.

Azorín FERnÁndez, D. y R. BAquero Mesa (2007): «Los americanismos en el Nuevo Diccionario de la Lengua Castellana de Vicente Salvá», Actas del II Congreso Internacional de Historia de la Lengua Española, Alicante, Biblioteca Virtual Miguel de Cervantes, pp. 963-970.

Bueno Morales, A. Ma (1996): «La lexicografía no académica del siglo XIX: el Diccionario Enciclopédico de la lengua española publicado por la editorial Gaspar y Roig», en M. Alvar Ezquerra, coord., Estudios de historia de la lexicografía del español, Málaga, Universidad de Málaga, pp. 151-157.

CABRÉ, M. ${ }^{\mathrm{a}}$ T. (1993): La terminología: teoría, metodología, aplicaciones, Barcelona, Ediciones Antártida.

CABRÉ, M. ${ }^{\mathrm{a}}$ T. (1999): La terminología. Representación y comunicación. Elementos para una teoría de base comunicativa y otros artículos, Barcelona, Universitat Pompeu Fabra.

Chambre de Commerce et D'Industrie de PARIS (1988): L'École commerciale de la Chambre de Commerce et d'Industrie de Paris: 125 ans d'enseignement commercial, París, Chambre de Commerce et d'Industrie de Paris.

Choppin, A., dir. (1995): Les Manuels scolaires en France de 1789 à nos jours: les Manuels d'espagnol, París, INRP.

Clavería NADAl, G. (2016): De vacunar a dictaminar: la lexicografía académica decimonónica y el neologismo, Madrid-Frankfurt, Iberoamericana-Vervuert.

Colón Doménech, G. (2002): «Elementos constitutivos del léxico español», Para la historia del léxico español, Madrid, Arco/Libros, vol. I, pp. 19-44. 
Esparza Torres, M. A. (1999): «Notas sobre el Diccionario Nacional de Ramón Joaquín Domínguez», en M. Á. Esparza Torres et al., eds., Estudios de Historiografía Lingüistica Hispánica ofrecidos a Hans-Josef Niederehe, Vigo, Publicaciones de la Universidad de Vigo, pp. 39-64.

ESPARZA TORRES, M. A. y H.-J. NiEDEREHE (2012): Bibliografía cronológica de la lingüística, la gramática y la lexicografía del español (BICRES IV). Desde el año 1801 hasta el año 1860, Amsterdam-Philadelphia, John Benjamins Publishing.

ESPARZA TORRES, M. A. y H. J. NiEDEREHE (2015): Bibliografía cronológica de la lingüística, la gramática y la lexicografía del español (BICRES V). Desde el año 1861 hasta el año 1899, Amsterdam-Philadelphia, John Benjamins Publishing.

García Belmar, A. y J. R. Bertomeu SÁnchez (1999): Nombrar la materia: Una introducción histórica a la terminología química, Barcelona, Ed. del Serbal.

GARRIGA ESCRIBANO, C. (1996): «Notas al léxico económico del siglo XVIII», en A. Alonso González et al., eds., Actas del III Congreso Internacional de Historia de la Lengua Española, Madrid, Arco/Libros, II, pp. 1279-1288.

GARRIGA ESCRIBANO, C. (1996-1997): «Penetración del léxico químico en el DRAE: la edición de $1817 »$, Revista de Lexicografia, III, pp. 59-80.

GARRIGA ESCRIBANO, C. (2001): «Sobre el Diccionario académico: la 12a ed. (1884)»»», en A. M. Medina Guerra, coord., Estudios de lexicografía diacrónica del español: (V Centenario del Vocabularium Ecclesiasticum de Rodrigo Fernandez de Santaella), Málaga, Universidad de Málaga, pp. 261-315.

GARRIGA ESCRIBANO, C. (2003): «La química y la lengua española en el silo XIX», Asclepio: Revista de historia de la medicina y de la ciencia, 55, 2, pp. 93-117.

GARRIGA ESCRIBANO, C. (2018): «Las voces de la química», en G. Clavería Nadal y M. Freixas, coords., El diccionario de la Academia en el siglo XIX: la $5^{a}$ edición (1817) al microscopio, Madrid, Arco/Libros, pp. 313-337.

GARRIGA EscribanO, C., S. IGLESIA MARTín y F. RodrígueZ (2013): «La documentación lexicográfica sobre el léxico especializado para la elaboración de un diccionario histórico: notas a propósito de la lexicografía española del siglo XIX», en G. Clavería Nadal et al., coords., Historia, lengua y ciencia, una red de relaciones, Berna, Peter Lang, pp. 139-156.

GILDO, D. y Ch. LE TOUZÉ (1857-1859): Manuel de correspondance commerciale en espagnol et en français suivi d'un Dictionnaire français-espagnol et espagnol-français, París, Bergelot.

GÓMEZ DE ENTERRÍA, J. (1996): Voces de la economía y el comercio en el español del siglo XVIII, Alcalá de Henares, Universidad de Alcalá.

GutiÉRreZ CUADRADO, J. (2001): «Lengua y ciencia en el siglo XIX español: el ejemplo de la química», en M. Bargalló et al., eds., Las lenguas de especialidad y su didáctica, Tarragona, Universitat Roviri i Virgili, pp. 181-196.

GUTIÉRREZ CUADRADO, J. (2004): «Las traducciones francesas, mediadoras entre España y Europa en la lengua técnica del siglo XIX», en V. Alsina, coord., Traducción y estandarización: la incidencia de la traducción en la historia de los lenguajes especializados, Madrid-Frankfurt, Iberoamericana-Vervuert, pp. 35-60.

Gutiérrez Rodilla, B. (1998): La ciencia empieza en la palabra. Análisis e historia del lenguaje científico, Barcelona, Península.

GutiÉRrez RodiLla, B. (2005): El lenguaje de las ciencias, Madrid, Gredos. 
IgLESIA MARTín, S. (2008): «El diccionario de R. J. Domínguez como ejemplo de la influencia de la lexicografía francesa en la lexicografía española del siglo XIX», en D. Azorín, ed., El diccionario como puente entre las lenguas y culturas del mundo. Actas del II Congreso Internacional de Lexicografía Hispánica, Alicante, Biblioteca Virtual Miguel de Cervantes, 2008, pp.121-127.

La Voz de México. Diario político, religioso, científico y literario de la «Sociedad Católica», México, Sociedad Católica, 9-VI-1897.

LAPESA, R. (1991): Historia de la lengua española, Madrid, Gredos.

PICHARDO Y TAPIA, E. (1836): Diccionario provincial de voces cubanas, Matanzas, Imprenta de la Real Marina.

Rodríguez Herrera, E. (1953): Pichardo novísimo, La Habana, Selecta.

Rodríguez HERRERA, E. (1958): Léxico mayor de Cuba, La Habana, Editorial Lex, 2 vols.

REAL ACADEMIA ESPAÑOLA (2017): Diccionario de la lengua española. $23^{\mathrm{a}}$ ed. actualizada. Disponible en http://dle.rae.es/?w=diccionario [junio-julio 2018].

ReAl ACADEMia EsPañola (2001): Nuevo Tesoro Lexicográfico de la lengua española. Disponible en http://www.rae.es/recursos/diccionarios/diccionarios-anteriores1726-1992/nuevo-tesoro-lexicografico [junio-julio 2018].

RONDEAU, G. (1983): Introduction à la Terminologie, Quebec, Gaëtan Morin.

SECO, M. (1987a): «El nacimiento de la lexicografía moderna no académica», Estudios de lexicografía española, Madrid, Paraninfo, pp. 129-151.

SECO, M. (1987b): «Ramón Joaquín Domínguez», Estudios de lexicografía española, Madrid, Paraninfo, pp. 152-164.

SECO, M. (1987c): «Un lexicógrafo romántico: Ramón Joaquín Domínguez», Estudios de lexicografía española, Madrid, Paraninfo, pp. 165-171. 